\title{
Práticas e eventos de letramento em pesquisas sobre escrita infantil
}

\section{Practices and events of literacy in research in children's writing}

\section{Prácticas y eventos de letramento en la investigación de la escritura de los niños}

\author{
(iD) Cristiane Carneiro Capristano \\ Universidade Estadual de Maringá (UEM), Maringá, Paraná, Brasil. \\ E-mail: capristano1@yahoo.com.br
}

\begin{abstract}
Resumo: Neste artigo, discute-se como as noções de prática e de evento de letramento, forjadas no âmbito dos Novos Estudos do Letramento, podem ser revisitadas por pesquisas sobre escrita infantil feitas no campo dos estudos da linguagem. Essa discussão é realizada, por um lado, colocando em relação as noções de práticas e eventos de letramento com as de memória e acontecimento e, por outro, examinando enunciados escritos infantis resultantes de práticas letradas escolares. Em homenagem ao trabalho de Silvia Lucia Bigonjal Braggio, procura-se mostrar como os enunciados infantis apontam para a miscibilidade das práticas presente nos eventos de letramento.
\end{abstract}

Palavras-chave: Práticas de letramento. Eventos de letramento. Escrita infantil.

\begin{abstract}
In this article, we discuss how the notions of practice and event of literacy, developed in the context of New Literacy Studies, can be revisited by research on children's writing in the field of language studies. This discussion is carried out by relating the notions of practices and events of literacy with those of memory and event and by examining children's written enunciations resulting from school practices of literacy.
\end{abstract}


In homage to Silvia Lucia Bigonjal Braggio's work, we seek to show how the children's statements point to the miscibility of practices present in events of literacy.

Keywords: Practices of literacy. Events of literacy. Child writing.

Resumo: En este artículo, se discute cómo las nociones de práctica y evento de letramento, forjadas dentro de los Nuevos Estudios de Letramento, pueden ser revisadas por la investigación sobre la escritura de los niños, realizada en los estudios del lenguaje. Esta discusión se lleva a cabo ubicando las nociones de prácticas y eventos de letramento con las de memoria y acontecimiento. Además, se examinan los escritos de los niños resultantes de prácticas escolares. En homenaje a la obra de Braggio, se busca mostrar cómo los escritos de los niños apuntan a la miscibilidad de las prácticas en los eventos de letramento.

Palabras-clave: Prácticas de letramento. Eventos de letramento. Escritura infantil.

Submetido em 23 de fevereiro de 2021.

Aceito em 08 de abril de 2021.

Publicado em 10 de setembro de 2021. 
Práticas e eventos de letramento em pesquisas sobre escrita infantil

Cristiane Carneiro Capristano

\section{Introdução}

As noções de prática e de evento de letramento são imprescindíveis para as pesquisas desenvolvidas sob a égide dos chamados Novos Estudos do Letramento (doravante, NEL). Em um texto publicado em 2000', justamente pelo reconhecimento do caráter basilar das noções, Street (2000) defendia a necessidade de uma maior precisão e de um uso mais criterioso, sobretudo, da noção de práticas de letramento. O autor argumentava serem poucos os pesquisadores no campo dos NEL preocupados em especificar os significados dessas expressões para os seus trabalhos, talvez por um acordo tácito de que elas teriam mais ou menos o mesmo sentido em todas as pesquisas desenvolvidas sob essa perspectiva. Para Street (2012), no entanto, a ausência de menção aos processos epistemológicos envolvidos na emergência das noções de prática e de evento de letramento colocava-as, às vezes, numa posição (temerária) de quase evidências².

Se para os estudiosos do letramento, no campo da pesquisa etnográfica, como pleiteava Street (2012), é essencial explicitar os contornos teóricos dessas noções, talvez ainda mais fundamental seja para os estudiosos que as deslocam de seu campo de origem e as acomodam em outros campos teóricos. Em minhas reflexões sobre a escrita da criança, tenho frequentemente trabalhado com as noções de prática e de evento de letramento, articulando-as, embora não de forma explícita, com a perspectiva enunciativo-discursiva assumida para a investigação dessa escrita ${ }^{3}$.

As pesquisas quetenho desenvolvido sobre escrita da criança não têm a mesma orientação epistemológica dos estudos etnográficos

\footnotetext{
1 Trata-se do texto Literacy events and literacy practices: theory and practice in the New Literacy Studies, publicado no livro Multilingual literacies, organizado por Marilyn Martin-Jons e Kathryn E. Jones, em 2000, traduzido, em 2012, para o português, em uma coletânea de artigos sobre letramento, organizada por Izabel Magalhães. Nas reflexões aqui desenvolvidas, toma-se como referência o texto traduzido.

2 Um passeio por esses estudos permite ver, no entanto, que, apesar da falta de explicitação, há convergências e, também, diferenças nas definições dos conteúdos das expressões, como sinalizava o próprio Street (2012), com base em exemplos e discussões. Assim, ainda que seja possível reconhecer um ponto de partida comum para a definição dessas noções entre as pesquisas no campo dos NEL - ponto de partida referente à condição do letramento como prática social, oposta à noção de letramento como uma habilidade técnica -, é importante reconhecer que o ponto de chegada pode variar.

$3 \mathrm{Em}$ meus trabalhos anteriores, essa perspectiva não é anunciada de forma explícita, mas creio ser possível reconhecê-la pelos objetivos e preocupações norteadoras dos trabalhos, estes sim explicitados - cf., sobretudo, Capristano (2007a, 2007b, 2013 e 2018); Capristano; Chacon (2014) e Capristano; Machado (2015) e Machado e Capristano (2016).
} 
e, por isso, não seria possível, a meu ver, incorporar as noções de práticas e eventos de letramento como elas são construídas nesses estudos, transpondo-as simplesmente para a análise de enunciados infantis. É necessária, portanto, uma reconstrução ou ainda uma integração dessas noções ao enquadramento teórico de partida.

Tendo as ponderações feitas até aqui como horizonte, neste artigo, busco fazer uma reflexão sobre práticas e eventos de letramento, alicerçada em diferentes contribuições dos estudos sobre a linguagem e, também, dos NEL. Com a aproximação desses distintos campos de pesquisa, procuro mostrar como esses conceitos podem ser revisitados no quadro teórico no qual se inscrevem as pesquisas que desenvolvo. Com isso, busco trazer alguma contribuição para as pesquisas sobre escrita infantil, no campo dos estudos sobre a linguagem, para as quais os conceitos de práticas e de eventos de letramento mostram-se relevantes.

Organizo a reflexão da seguinte maneira: começo retomando o modo como Street (2012 e 2014) define práticas e eventos de letramento no campo da pesquisa etnográfica, como forma de apresentar uma interpretação dessas noções no seu campo primeiro de emergência. A seleção desses estudos justifica-se por neles se encontrar uma discussão teórica e analítica das noções de prática e de evento letramento bastante importante para os pesquisadores interessados no tema. Depois, busco articular o modo como Street (2012 e 2014) delineia essas noções com os conceitos de "memória" e de "acontecimento", tal como desenhados em Pêcheux (2010) e apropriados por Corrêa (2007a, 2007b e 2013). Com base nessa articulação, discuto, por fim, relações possíveis entre eventos e práticas de letramento, examinando enunciados escritos infantis, resultantes de eventos de letramento escolares. Em homenagem ao trabalho da Profa. Dra. Silvia Lucia Bigonjal Braggio, e inspirada por suas reflexões sobre a aquisição da escrita, procuro mostrar o modo como os enunciados infantis (um coletado e analisado pela professora e outro por mim) apontam para a "miscibilidade das práticas sociais" (CORRÊA, 2007a) que ganham lugar nos eventos de letramento. 


\section{Eventos e práticas de letramento no campo da etnografia}

Em vários momentos de suas reflexões sobre letramento, por exemplo, Street (2012), o autor preocupa-se em circunscrever fronteiras entre práticas e eventos de letramento, bem como situar teoricamente como entende essas noções, já que, para os propósitos de sua reflexão em defesa do entendimento da escrita como uma prática social (e não como uma tecnologia, como uma habilidade ou uma competência), elas são noções fulcrais. Para os propósitos deste artigo, serão explorados, embora não de forma exaustiva, apenas dois trabalhos do autor, traduzidos para o português, nos quais ele se empenha em discutir, de forma explícita, os contornos teóricos dessas noções: Street (2012 e 2014).

Street (2012, p. 74) afirma que a noção de prática de letramento foi empregada em seus trabalhos, inicialmente, com a finalidade de dar destaque para as práticas e para as concepções sociais de leitura e de escrita. Mais tarde, o autor redefine a noção de prática de letramento com o propósito de explicar tanto os eventos de letramento quanto os modelos sociais de letramento "a que os participantes recorrem nos eventos e que lhes dão significados (STREET, 1988)" (STREET, 2012, p. 74). Avaliação semelhante aparece também em Street (2014, p. 18). Para ele, as práticas de letramento são tidas como se referindo "ao comportamento e às conceitualizações sociais e culturais que conferem sentido aos usos da leitura e/ou da escrita". Citando Barton (1991 apud STREET, 2012, p. 18), o autor também considera as práticas de letramento como modos culturais gerais de utilização do letramento aos quais as pessoas recorreriam num evento letrado; funcionariam como um conjunto de habilidades e convenções próprias de um grupo (cf. STREET, 2014, p. 37).

As práticas de letramento teriam, além disso, natureza ideológica e cultural. Seriam formas específicas, sociais e ideologicamente construídas que "habitamos e usamos em determinados 
momentos" (STREET, 2014, p. 23). Na visão etnográfica, segundo Street (2014), as práticas são atravessadas por relações de poder e constituiriam lugares de disputa ideológica. Nas práticas letradas institucionalizadas pela escola, por exemplo, segundo o autor, os alunos não estariam aprendendo apenas a codificar e decodificar um sistema de escrita ou ainda a usar uma determinada caligrafia, mas, sobretudo, estariam aprendendo modelos culturais de identidade e personalidade tidos como importantes pela instituição escolar (cf. STREET, 2014, p. 154).

Os diferentes contornos dados à noção de prática de letramento têm a finalidade de assinalar um afastamento da interpretação das práticas como um mero conjunto de habilidades e competências individuais, produto exclusivo de experiências subjetivas, descontextualizadas e neutras, como aquela que vigora na noção de letramento nomeada por Street, em vários de seus trabalhos, como autônoma. É possível supor também que, nesses diferentes contornos, repousa o desejo de uma articulação entre duas dimensões das práticas: uma mais individual - marcada, nas definições mencionadas, pela utilização de noções como comportamento e conjunto de habilidades - e uma coletiva ou social - marcada pela utilização de noções como concepções, conceitualizações (sociais e culturais), modos culturais, convenções, modelos. A dimensão mais individual comportaria os usos, as habilidades e as competências de leitura e de produção escrita desenvolvidas pelos indivíduos nas relações com seus grupos sociais, enquanto a dimensão social seria equivalente às regras, aos padrões, às convenções e/ ou aos modelos socioculturais que permitem a emergência dos usos, das habilidades e das competências de leitura e de escrita.

Ao contrário da interpretação autônoma do letramento, na qual a dimensão social das práticas de leitura e de escrita é ignorada, a noção de prática de letramento, defendida por Street, supõe uma relação intrínseca entre essas duas dimensões. Sem negar as habilidades e/ou competências como uma das dimensões do letramento, busca-se entendê-las como encapsuladas "em todos culturais e em estruturas de poder" (STREET, 2014, p. 172), ou seja, 
as habilidades e/ou as competências só podem ser plenamente compreendidas à luz da dimensão social do letramento que, por sua vez, envolve a consideração do papel das relações de poder, da cultura e das ideologias dos grupos aos quais os indivíduos pertencem. Não há cisão entre as duas dimensões; elas coexistem, dependem uma da outra.

Outra característica bastante importante das práticas de letramento na visão de Street (2012) - também apreendida nas definições supramencionadas - refere-se ao fato de os usos e os significados do letramento ganharem sentido apenas em contextos sociais reais, ou seja, eles estariam sempre associados às vidas locais, cotidianas, diárias (STREET, 2014, p. 69) e, também, aos significados, conceitos de identidade e epistemologias locais (STREET, 2014, p. 124). Para Street (2012 e 2014), cada grupo social funciona como um microcosmo relativamente autônomo, um espaço de relações objetivas, em que os usos da leitura e da escrita são feitos a partir de necessidades e interesses específicos do grupo, irredutíveis ao funcionamento de outros grupos sociais. As práticas de letramento seriam, nesse sentido, padrões, convenções ou modelos particulares criados e reproduzidos em contextos reais, autênticos e específicos (cf. STREET, 2014, p. 24).

Assim circunscrito, o conceito de práticas de letramento, de acordo com Street (2014 p. 18), estaria num nível mais alto de abstrações do que o de evento de letramento. Como historiciza o autor, retomando Barton (1994 apud STREET, 2012), o evento de letramento surge como conceito numa analogia ao evento de fala - expressão cunhada no âmbito da sociolinguística - e se referiria a atividades particulares, regulares e repetidas, nas quais o letramento ou, mais propriamente, a escrita teria um papel. Pode ser considerado, também, como faz Heath (1982), como "qualquer ocasião em que um fragmento de escrita integra a natureza das interações dos participantes e seus processos interpretativos" (HEATH, 1982, apud STREET, 2014, p. 173).

A noção de prática de letramento, nos trabalhos de Street, surge como um desenvolvimento do conceito de eventos de letramento, como formulado por Heath, e, segundo o autor, passa a in- 
Práticas e eventos de letramento em pesquisas sobre escrita infantil Cristiane Carneiro Capristano

corporar “não só os 'eventos de letramento', ocasiões empíricas às quais o letramento é essencial, mas também modelos populares desses eventos e as preconcepções ideológicas que os sustentam" (STREET, 2014, p. 18). Dessa perspectiva, uma prática de letramento englobaria não só o evento, entendido como a situação presencial e empírica (a ocasião) na qual se faz uso real da escrita, mas, também, padrões, convenções ou modelos socioculturais ideologicamente constituídos que tornariam as situações possíveis. $\mathrm{Na}$ perspectiva etnográfica, defendida por Street, evento e prática de letramento são, por conseguinte, noções com estatutos diferenciados: enquanto a primeira refere-se às ocasiões particulares nas quais os usos da escrita acontecem e podem ser observados pelos pesquisadores - inclusive filmados, fotografados, descritos -, a segunda refere-se ao amálgama dessas ocasiões, àquilo que é, de forma contraditória, invisível e determinante delas: padrões, modelos e/ou convenções socialmente construídos que viabilizam e sustentam certos usos da escrita e não outros.

A utilização da noção de evento de letramento, de forma isolada do de prática, pode tornar-se um problema, uma vez que confere à noção e, por conseguinte, à pesquisa que a utiliza de forma isolada, um caráter meramente descritivo "e, do ponto de vista antropológico, não nos diz [diria] como os significados [para a escrita] são construídos" (STREET, 2012, p. 76). Para pesquisa etnográfica como proposta por Street, não basta descrever e documentar os eventos; é necessário chegar aos comportamentos regulares e às conceitualizações relacionadas ao uso da leitura e/ou da escrita, ou seja, às práticas de letramento.

\section{Práticas e eventos de letramento numa perspectiva enunciativo-discursiva}

Como particularizados em Street (2012 e 2014), quais matizes podem ganhar os conceitos de prática e de evento de letramento - bem como a relação entre eles - quando deslocados para a 
investigação da escrita infantil, no campo dos estudos sobre a linguagem? A resposta a essa questão, sem dúvida, passa pela consideração de que uma prática de letramento é, antes de tudo, uma prática de linguagem e, portanto, os contornos dados às noções de prática e de evento de letramento estarão na dependência do como se postula o funcionamento da linguagem e de seus modos de enunciação. Embora a pesquisa etnográfica não ignore a relação entre letramento e linguagem, a discussão sobre ela não ganha, nesse campo, o teor vital que recebe (ou deveria receber) em pesquisas sobre letramento feitas no campo dos estudos sobre a linguagem.

Há algum consenso entre os linguistas (teóricos e aplicados) de que, em seu campo de pesquisa, paradoxalmente, não há consenso sobre o que é a linguagem. Antes de um campo homogêneo, veem-se variadas formas de interpretação da linguagem convivendo, em relações ora solidárias, ora antagônicas. Como consequência, para responder a essa questão, também é necessário recortar, no amplo campo dos estudos sobre a linguagem, um lugar de observação. Seguindo a trilha aberta por trabalhos de Corrêa (2004, 2007a, 2007b, dentre outros), o ponto de vista a partir do qual tenho buscado entender o funcionamento da escrita infantil é balizado pelo questionamento da transparência da linguagem, pela oposição radical à consideração do sujeito como origem dos sentidos e pela colocação da dimensão histórica das práticas linguísticas como centro das reflexões. Deste ponto de vista, o entendimento das práticas e dos eventos de letramento não pode furtar-se, portanto, da consideração da opacidade da linguagem - e, como consequência, da heterogeneidade constitutiva de seus modos de enunciação (cf. CORRÊA, 2004); da alteridade como condição para a emergência do sujeito e da linguagem; e, por fim, da historicidade das práticas linguísticas (cf., por exemplo, TFOUNI, 2010; TFOUNI, MONTE-SERRAT e MARTHA, 2013).

No que segue, revisito as noções de prática e de evento de letramento, como delineados em Street, considerando essas três dimensões. Dados os limites da reflexão proposta neste artigo, 
Práticas e eventos de letramento em pesquisas sobre escrita infantil Cristiane Carneiro Capristano

tomo como eixo organizador a dimensão histórica das práticas e dos eventos de letramento, ficando, portanto, alteridade e opacidade em segundo plano. Discuto, em especial, o pressuposto etnográfico de que as práticas se constituem no amálgama dos eventos de letramento com padrões, modelos e/ou convenções social e localmente construídos. São deixadas também para discussões futuras outras dimensões das práticas, como vistas na pesquisa etnográfica, por exemplo: seu papel na construção de identidades, sua faceta ideológica e sua vinculação a relações de poder.

Numa aproximação ao proposto por Foucault (2004, p. 153)4 a respeito do funcionamento das práticas discursivas, pode-se entender uma prática de letramento como um conjunto de regras relativamente anônimas e sempre fundamentalmente históricas, responsáveis por delimitar, "em uma dada época, e para uma área social, econômica, geográfica ou linguística dada", o que pode e deve ser dito/escrito/lido/visto em determinado tempo/espaço. Além de estabelecer a conjuntura para a emergência dos eventos de letramento, as práticas de letramento articulam lugares e posições discursivas e produzem um campo de regularidades para as diversas e dispersas possibilidades de subjetividade. Ou seja, as práticas de letramento estabelecem condições de emergência e de exercício das funções enunciativas vistas nos eventos de letramento. O sujeito emerge em eventos de letramento sempre a partir de contradições de um determinado lugar/posição social - o de professor, aluno, pai, colega, para ficar nos exemplos mais comuns encontrados no âmbito da instituição escolar -, que é afetado por diferentes relações de poder, vistas como condições institucionais contraditórias, historicamente constituídas, legitimadoras e fundadoras dos eventos.

Aceitando a aproximação, é preciso considerar também que o funcionamento de uma prática de letramento não pode ser reduzido, no entanto, a determinantes sociais, econômicos e culturais

\footnotetext{
4 Nas linhas que seguem, trago conceitos e reflexões de diferentes quadros teóricos, sobretudo do quadro complexo e não homogêneo da chamada Análise do Discurso Francesa. Exploro-os de forma relativamente livre, nem sempre tornando explícitos o tempo e o espaço nos quais esses conceitos e reflexões foram concebidos e as eventuais diferenças entre eles. Para outros estudos, talvez eles pudessem ser distanciados em função de suas filiações e preocupações, mas, aqui, cumprem apenas o papel de permitir uma reflexão sobre as noções de prática e evento de letramento.
} 
ou a mero reflexo de uma conjuntura e de lugares e posições discursivas estáveis e homogêneas. As condições de existência e de aparecimento das práticas de letramento não são, desta forma, meramente repetidas nos eventos. Ademais, as condições não formariam, portanto, apenas um conjunto de convenções modelares e padronizadas habitadas pelos sujeitos e usadas em determinados momentos e espaços. Ou seja, não reproduziriam modelos ou convenções dados de antemão, pertencentes a um grupo particular e distribuídos quase que homogeneamente para esse grupo. Para entender o funcionamento das práticas de letramento de uma perspectiva linguística, não basta olhar para o que se repete, é preciso considerar também os pontos de ruptura - cf. Foucault (2004) -, momentos em que, de forma contraditória, a atualização das práticas não se mostra tal e qual se esperaria dada a conjuntura na qual ela ocorre.

Além disso, deve-se considerar outro fator também não ponderado pela pesquisa etnográfica: o repetível de uma prática - observado num evento de letramento - é da ordem de um já dito - já escrito, já lido, já visto... - e sinaliza para a memória do dizer (PÊCHEUX, 2010), lugar onde saberes de diferentes ordens, vindos das experiências simbólicas, social e historicamente edificadas, vividas pelos sujeitos em diferentes tempos/espaços, encontram-se reunidos, de forma muitas vezes fragmentada, contraditória e lacunar, num jogo que envolve, ao mesmo tempo, lembranças e esquecimentos. Essa memória, longe de constituir-se como uma capacidade cognitiva individual, um simples depósito de informações recolhidas e armazenadas de uma coletividade; ou, ainda, como uma mera lembrança de fatos ou de vivências passados, é entendida como a exterioridade que sustenta a emergência dos sujeitos e dos eventos e que se constitui como " um espaço móvel de divisões, de disjunções, de deslocamentos e de retomadas, de conflitos de regularização. Um espaço de desdobramentos, réplicas, polêmicas e contra-discursos" (PÊCHEUX, 2010, p. 56).

Portanto, a memória do dizer não é um espaço inerte, no qual estariam depositadas lembranças restituídas pelo sujeito num 
evento de letramento, mas, contrariamente, um espaço vivo e dinâmico no qual convivem lembranças e esquecimentos ligados às experiências simbólicas dos sujeitos e aos determinantes sócio-históricos dessas experiências - cf. Corrêa (2007a, 2007b e 2013). Uma prática refere-se, pois, também ao que está inscrito nas lembranças e nos esquecimentos que afloram, indiciariamente, por meio dos/nos sujeitos, a cada novo evento de letramento.

Essa forma de interpretar as práticas permite vislumbrar também outra possibilidade de compreender os eventos, inicialmente definidos, no campo da pesquisa etnográfica, como uma ocasião em que a escrita se torna essencial para a interação entre indivíduos ou entre grupos sociais. Sem negar a dimensão empírica dos eventos - que, de fato, mostram-se, num primeiro momento, como ocasiões em que a escrita é usada -, entendo que um evento de letramento é, antes de tudo, um acontecimento, no sentido proposto por Corrêa (2007a, 2007b e 2013), a partir de uma apropriação da reflexão de Pêcheux (2006 e 2010).

Corrêa (2013, p. 491-492) recusa a ideia de que um acontecimento possa ser identificado com uma situação previsível em que uma atividade linguística é realizada, ou ainda, que ele possa se referir apenas a um evento datado ou social e geograficamente circunscrito. $\mathrm{O}$ acontecimento refere-se ao processo sócio-histórico envolvido na tomada da palavra por um sujeito - ambos, palavra e sujeito, constituídos nesse mesmo processo. Além disso, um acontecimento depende das redes de memória e dos trajetos sociais nos quais irrompe e marcaria sempre "a possibilidade de uma desestruturação-reestruturação dessas redes e trajetos" (PÊCHEUX, 2006, p. 56-57).

É com base nessas proposições que Corrêa busca entender o acontecimento como "uma questão de experiência - tanto no sentido da novidade que toda reapresentação da experiência traz, quanto no sentido de retomada do já experimentado, o que permite entender experiência também como memória" (2013, p. 204). Do ponto de vista de Corrêa (2007a), as experiências sociais não 
Práticas e eventos de letramento em pesquisas sobre escrita infantil Cristiane Carneiro Capristano

são memórias do já vivido empírico, uma vez que, muitas vivências simbólicas

escapam à remissão a uma ocorrência linguística particular, mas podem ser pensadas, por exemplo, como feixes de enunciados que, de idades e de espaços díspares, se cruzam e atuam, por recorrência ou apagamento, sobre a dispersão das lembranças para compor uma memória (CORRÊA, 2007b, p. 204).

Entendido como um acontecimento, um evento de letramento poderia, então, ser definido como um processo sócio-histórico que envolve um ato de apropriação da escrita pelo sujeito, ambos, escrita e sujeito, constituídos nesse mesmo ato. O uso da expressão "ato de apropriação da escrita" não significa, é necessário lembrar, o ato de usar (e saber usar) a escrita como tecnologia. A apropriação da escrita se dá via inscrição do sujeito em práticas letradas diversas, social e historicamente constituídas, independente da condição de alfabetizado ou não alfabetizado do sujeito (cf., a esse respeito, os diversos trabalhos de Tfouni, em especial, TFOUNI, 2010).

Um evento de letramento é, também, um elo (no sentido bakhtiniano) na cadeia de outros eventos, sempre dependente das redes de memória e dos trajetos sociais nos quais irrompe. Estaria, da mesma forma, marcado, desde sempre, pela "possibilidade de uma desestruturação-reestruturação dessas redes e trajetos" (PÊCHEUX, 2006, p. 56-57), tratando-se, assim, de uma atualização contraditória (já que envolve a possibilidade de desestruturação-reestruturação) das experiências simbólicas vividas pelos sujeitos, experiências estas não reduzidas às situações ou às circunstâncias empíricas das quais o sujeito participou como protagonista e/ou coadjuvante. Embora situações e circunstâncias façam parte do vivido e do experimentado pelo sujeito, elas constituem apenas uma dimensão do vivido e do experimentado. Na perspectiva enunciativo-discursiva assumida aqui, o vivido e o experimentado "escapam à remissão a uma ocorrência linguística particular" 
Práticas e eventos de letramento em pesquisas sobre escrita infantil Cristiane Carneiro Capristano

(CORRÊA, 2007b, p. 204). São vivências e experiências simbólicas nascidas nas relações com a alteridade constitutiva do sujeito e do seu dizer, não necessariamente caudatárias da participação direta do sujeito numa situação ou numa circunstância.

Alinhavando as reflexões feitas até aqui, pode-se dizer que uma prática de letramento se mostra como aquilo (por exemplo, regras, lugares, posições, certos arranjos de tempo/espaço) que é possível de se tornar presente, por um efeito de memória (em que estão conjugados lembranças e esquecimentos sócio-historicamente constituídos), num evento de letramento. Nessa reapresentação da noção de prática, é possível notar que, assim como previsto na perspectiva etnográfica defendida por Street, evento e prática de letramento são noções que, embora intimamente relacionadas, têm estatutos diferentes. No entanto, da perspectiva proposta aqui, o evento de letramento deixa de ter um caráter apenas empírico e descritivo, para entrar numa outra ordem: um evento de letramento, compreendido como um acontecimento, configura-se como um nó em uma rede (FOUCAULT, 2004, p. 26), ponto de encontro entre uma novidade e uma memória (cf. CORRÊA, 2013, p. 335), momento de atualização (sempre contraditória, já que efeito de lembranças e de esquecimentos) de práticas sócio-históricas (TFOUNI, 2010) vivenciadas simbolicamente pelos sujeitos em diferentes tempos e espaços. Visto desta forma, o evento de letramento migra da posição sobretudo descritiva, que parece ocupar na pesquisa etnográfica, para uma posição mais nuclear: torna-se condição e ponto de partida para entender o funcionamento dinâmico e heterogêneo das práticas de letramento.

\section{Os eventos-acontecimentos ${ }^{5}$ nos quais emerge a escrita da criança}

Considerando as reflexões feitas até aqui, discuto, na sequência, relações possíveis entre eventos e práticas de letramento

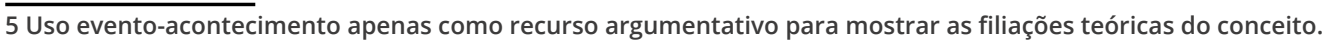


Práticas e eventos de letramento em pesquisas sobre escrita infantil

Cristiane Carneiro Capristano

(como redesenhados acima), com base no exame de dois enunciados escritos infantis, resultantes de práticas e eventos de letramento escolares. Em homenagem ao trabalho da Profa. Dra. Silvia Lucia Bigonjal Braggio e inspirada por suas reflexões sobre a aquisição da escrita, procuro mostrar o modo como os enunciados infantis (um coletado e analisado pela professora e outro por mim) apontam para a "miscibilidade das práticas sociais" (CORRÊA, 2007a) que ganham lugar nos eventos de letramento.

Um dos enunciados foi apresentado no artigo intitulado " $\mathrm{A}$ importância da construção do sentido na aquisição da linguagem escrita", publicado em 1995, no livro Contribuições da linguística para alfabetização, organizado por Braggio (1995). Nesse capítulo, escrito pela autora, a proposta era mostrar como se dava a aquisição da escrita no interior de uma sala de aula, cujas atividades didáticas estavam calcadas numa visão sociopsicolinguística ${ }^{6}$ da aquisição da escrita. A escolha desse enunciado não é aleatória, mas está relacionada com uma experiência pessoal, relatada na sequência.

Li o capítulo supracitado pela primeira vez em 2001, por ocasião do ingresso no curso de mestrado. Na leitura, deparei-me com a descrição de um evento de letramento, em muitos aspectos, semeIhante a eventos nos quais tinha atuado como protagonista quando trabalhava como professora alfabetizadora, em escolas da rede pública de São José do Rio Preto, no interior de São Paulo, entre os anos de 1997 e 2000. O evento relatado por Braggio (1995) contava com uma atividade de produção textual, realizada em sala de aula, calcada na reescrita da narrativa de um livro intitulado $A$ Margarida Friorenta7 ${ }^{7}$. Segundo informações fornecidas por Braggio (1995), a proposta foi feita nos primeiros dias de aula de uma sala de alfabetização guiada por uma abordagem sociopsicolinguística. Por meio dessa proposta, buscava-se averiguar os conhecimentos prévios

\footnotetext{
6 Em linhas gerais, uma visão sociopsicolinguística da aquisição da escrita, como proposta por Braggio (1992, 1995), está alicerçada em contribuições da Linguística e da Psicologia (nomeadamente, nas diversas contribuições de Lev Semionovitch Vygotsky) e tem como força motriz a construção dos sentidos pelos sujeitos envolvidos nas diferentes práticas de ensino e de aprendizagem. A premissa básica da abordagem sociopsicolinguística é a de que a aquisição da escrita reside no "intento semântico" compartilhado entre a criança e o outro com o qual a criança estabelece uma relação dialógica, em contextos concretos de produção sócio-histórico-ideológica. Para a autora, "a criança vai se apropriando das formas, estruturas e convenções da linguagem escrita para alcançar seus objetivos, isto é, o de dizer alguma coisa alguém por uma determinada razão" (BRAGGIO, 1995, p. 126). Do ponto de vista norteador da perspectiva, a aquisição da escrita começa muito antes de a criança chegar à escola e ocorre no curso de interações significativas com os diversos pares com os quais a criança convive.

7 ALMEIDA, F. L. A margarida friorenta. São Paulo: Editora Ática, 1988.
} 
Práticas e eventos de letramento em pesquisas sobre escrita infantil Cristiane Carneiro Capristano

das crianças sobre escrita. Para realizar a atividade, a história foi lida e, depois, recontada e dramatizada por alguns alunos da sala. Ao final, foi solicitado às crianças que representassem a história por meio de um desenho e a reescrevessem "do modo como podiam ou sabiam" (BRAGGIO, 1995, p. 129, itálico da autora). A autora apresenta e analisa um enunciado produzido como resposta a essa solicitação, feito por uma criança, nomeada como Mariana, reproduzido na sequência8:

\author{
A vovó é bonito \\ O vovô é bonito \\ A mamãe é bonita \\ O papai é bonito \\ (BRAGGIO, 1995, p. 130).
}

Seguindo a análise da autora, o enunciado escrito por Mariana é constituído por quatro frases, muito parecidas, nas quais é alterado apenas o elemento designado pela qualidade de "ser bonito": o vovô, a vovó, o papai, a mamãe. São frases mecanizadas, isoladas, grafofonicamente controladas e artificiais, não relacionadas com o conteúdo da história lida, uma vez que são "semanticamente desprovidas de sentido, naquele dado contexto" (BRAGGIO, 1995, p. 129). Para a autora, nesse enunciado, Mariana não estava preocupada em construir sentidos, mas, sim, "em escrever o que sabia, ou melhor, o que conseguia escrever a fim de se desincumbir de uma tarefa que, seguramente, enquanto atividade de sala de aula, Ihe era desconhecida" (BRAGGIO, 1995, p. 129).

Braggio (1995) calcula que, muito provavelmente, foi o método ao qual Mariana foi submetida, em sua inscrição escolar anterior (ela havia passado por uma "Pré-escola", na qual eram utilizados métodos voltados para a forma da língua, em si mesma, em detrimento da construção de sentidos), o fator determinante da

8 Braggio (1995) apresenta apenas a versão digitada do texto. 
concepção sobre a natureza da escrita apresentada por ela. Na sequência do capítulo, a autora analisa outros enunciados produzidos por essa criança, não tematizados aqui, a partir dos quais é possível ver Mariana sobre o efeito de novas experiências simbólicas, começando "a perceber [...] o papel do sentido no material escrito" (BRAGGIO, 1995, p. 130).

À luz das reflexões desenvolvidas na seção anterior, pode-se afirmar também que o enunciado produzido por Mariana é parte de um evento de letramento no qual convivem práticas de letramento em conflito: de um lado, práticas de letramento consideradas válidas e satisfatórias por uma perspectiva de aquisição da escrita guiada por uma visão sociopsicolinguística, por meio da qual se esperava a emergência de um "intento semântico" diferente do demonstrado por Mariana - reduzido ao cumprimento de uma tarefa, como observa Braggio (1995). Ou seja, um intento capaz de sinalizar para um discurso próprio, no qual aparecesse a voz de Mariana ou, ainda, no qual ela se mostrasse, de forma efetiva, como autora de seus enunciados, recuperando as dimensões significativas da história com a qual entrara em contato.

Por outro lado, também vemos emergir, nesse evento, práticas de letramento fundadas numa visão mecanicista da escrita, trazidas por Mariana, a fim de responder à demanda de reescrever a história A Margarida Friorenta, "do modo como podia ou sabia". Não é uma particularidade de Mariana a produção de frases mecanizadas, isoladas, grafofonicamente controladas e artificiais. Como assevera Braggio (1995), essa prática de produção escrita era (e, em alguns espaços, ainda é!) muito comum em práticas letradas escolares calcadas em métodos centrados em explorar a forma da escrita, ou, em outras palavras, em trabalhar, de forma redutora, apenas com a dimensão estritamente técnica da escrita, tomando essa dimensão como se fosse a própria escrita. O chamado "método das cartilhas" é um exemplo. Nesse método, a aquisição da escrita é vista como um processo mecânico, de codificação e de decodificação, no qual a criança aprenderia a escrever por meio da repetição e da memorização de estruturas consideradas basilares 
da escrita, começando por estruturas menores e mais simples fonemas e grafemas em relações biunívocas, por exemplo - e, depois, passando, aos poucos e de forma controlada pelo professor, para unidades maiores e mais complexas - registro e leitura de sílabas simples, sílabas complexas, palavras (em geral, descontextualizadas), frases e orações.

Nesses métodos, já acertadamente bastante criticados, a construção de sentidos e a produção de textos não entram como dimensões ensináveis da escrita: são meras consequências naturais e óbvias da aquisição da "escrita" - ou, melhor, do domínio de apenas uma dimensão (técnica) da escrita. Os vários trabalhos de Braggio (ver, por exemplo, 1992 e 1995) e de outros pesquisadores, interessados na escrita infantil e na aquisição da escrita, têm demonstrado que essas práticas (e a consequente redução da escrita a uma atividade técnica) são danosas e silenciam várias outras importantes dimensões da escrita e, principalmente, a meu ver, sua condição como modo de enunciação.

As reflexões feitas até aqui permitem afirmar que o enunciado de Mariana está sob condições de emergência, contraditoriamente dadas por práticas letradas distintas. Não é difícil supor que Mariana, em certo sentido, ao registrar o enunciado acima, sabia não estar escrevendo sobre $A$ Margarida Friorenta e, nessa direção, sabia não estar respondendo a uma parte da solicitação feita à ela. No entanto, é certo que ela escreveu do modo "como podia ou sabia", amparada em suas vivências simbólicas anteriores, que Ihe permitiram construir uma imagem de que escrever do modo "como podia ou sabia" era escrever ortograficamente de acordo com o esperado pelo professor, seguindo os modelos apresentados em outros eventos de letramento dos quais participou, em que outras práticas letradas (ainda que pouco eficazes e reducionistas) eram acionadas.

Ajustando a lente para o enunciado produzido por Mariana, nota-se também que um evento de letramento (e as práticas por ele atualizadas) não se constitui como uma mera repetição de eventos anteriores. Não se pode negar que Mariana produziu fra- 
ses mecanizadas, isoladas, grafofonicamente controladas e artificiais (BRAGGIO 1995, p. 129), decerto apresentadas para ela como modelos de boa escrita. No entanto, seu enunciado não é um mero decalque, uma mera reprodução de modelos. Em seu enunciado também se vê, por exemplo, uma alteração, embora mínima, desses modelos.

Explico-me: as palavras vovô e vovó, recuperadas por Mariana, distintas semanticamente, formam um par mínimo e se diferenciam, do ponto de vista fonológico, apenas com relação ao último fonema: uma vogal média alta, no caso de vovô, e uma vogal média baixa, em vovó. Do ponto de vista gráfico, distinguem-se apenas pela alternância entre acento agudo (vovó) e acento circunflexo (vovô). No texto produzido por Mariana, a diferença semântica, fonológica e gráfica entre vovô e vovó é considerada na introdução dessas palavras na posição de sujeito das frases "A vovó é bonito" e "O vovô é bonito" - momento no qual se verifica concordância de gênero entre o determinante e o nome. Essa diferença, no entanto, não é mantida com introdução do predicado "é bonito": a diferença entre "vovô" e "vovó" é aparentemente "esquecida" por Mariana, quando introduz esse predicado. O que significa o esquecimento da Mariana?

Para entender esse "esquecimento", é necessário lembrar que o funcionamento das práticas de letramento, tal como pensado neste artigo, não pode ser mensurado considerando apenas o quê delas se repete num evento de letramento, é preciso sopesar também os pontos de ruptura, momentos nos quais a atualização das práticas não se mostra tal e qual se esperaria. O evento de letramento analisado aqui é um acontecimento, nascido como um elo (no sentido bakhtiniano) na cadeia de outros acontecimentos, sempre dependente das redes de memória e dos trajetos sociais nos quais irrompe. Nele, a atualização de um modelo de boa escrita é atravessado pela atuação de outros fatos (pontos de ruptura), como, por exemplo, os efeitos da proximidade semântica, fonológica e gráfica entre as palavras vovô e vovó na produção escrita de 
Práticas e eventos de letramento em pesquisas sobre escrita infantil Cristiane Carneiro Capristano

Mariana; atuação que impediu a emergência de uma reprodução rígida de um modelo considerado de boa escrita?

Também o enunciado apresentado na Figura 1 permite refletir sobre o funcionamento das práticas e dos eventos de letramento aqui tematizados. Esse enunciado foi coletado por mim, quando atuava como professora alfabetizadora, em uma escola da rede municipal (pública) de São José do Rio Preto (SP). Nesse período, ainda sem conhecer o trabalho de Braggio (1995, 1992, por exemplo), mas já bastante afetada pelo discurso sobre alfabetização veiculado, sobretudo, pelos Parâmetros Curriculares Nacionais (PCNs) - discurso que, em muitos aspectos, mantém fortes elos com as reflexões de Braggio (1992, 1995) -, desenvolvi um trabalho de alfabetização centrado na produção de textos. Dentre as várias atividades de produção textual desenvolvidas com meus alunos, figurou uma na qual, coincidentemente, as crianças tiveram que reescrever parte da história A Margarida Friorenta, "do modo como podiam ou sabiam". A atividade foi proposta para crianças que, à época, estavam no início do segundo semestre letivo da primeira série do ensino fundamental.

Diferentemente do evento de letramento relatado por Braggio (1995), as crianças não tiveram contato inicial com a totalidade da história do livro: A Margarida Friorenta, pois a leitura da história foi interrompida quando a "Borboleta Azul" teve uma ideia. Os trechos do livro lidos para as crianças foram os seguintes:

Era uma vez uma Margarida num Jardim. Quando ficou de noite, a Margarida começou a tremer. Aí, passou a Borboleta Azul. A borboleta parou de voar. - Por que você está tremendo? - Frio! - Oh! É horrível ficar com frio! E logo numa noite tão escura! A Margarida deu uma espiada na noite. E se encolheu nas suas folhas. A borboleta teve uma ideia: - Espera um pouco!... ${ }^{10}$

\footnotetext{
9 Sem dúvida, pode-se encontrar enunciados produzidos por crianças constituídos apenas pela repetição, de forma rígida, de modelos de boa escrita, como os mencionados aqui, portanto, enunciados nos quais não se pode localizar pontos de ruptura explicitamente marcados. Dada a perspectiva enunciativo-discursiva assumida aqui, a inexistência de pontos de rupturas visíveis não significa, porém, ausência de rupturas, mas, talvez, apenas ausência de registros de rupturas nos enunciados das crianças e nos eventos dos quais eles são parte constitutiva.

10 Para acesso a uma leitura desse livro, feita em vídeo, conferir link: https://www.youtube.com/watch?v=ZCAPsFKIvhI. Último acesso em: 11 fev. 2021
} 
Práticas e eventos de letramento em pesquisas sobre escrita infantil Cristiane Carneiro Capristano

Depois da leitura do trecho acima e da apresentação das imagens que o acompanhavam, a proposta foi a de que as crianças continuassem a história e propusessem um final "do modo como podiam ou sabiam". Elas foram instigadas a pensar sobre o que teria acontecido entre a Borboleta Azul e a Margarida e, em particular, sobre o que a Borboleta Azul teria feito (quais ideias teria tido) para ajudar a Margarida. Na Figura 1, é reproduzido um exemplo de resposta a essa demanda ${ }^{11}$ :

Figura 1: A margarida e o frio

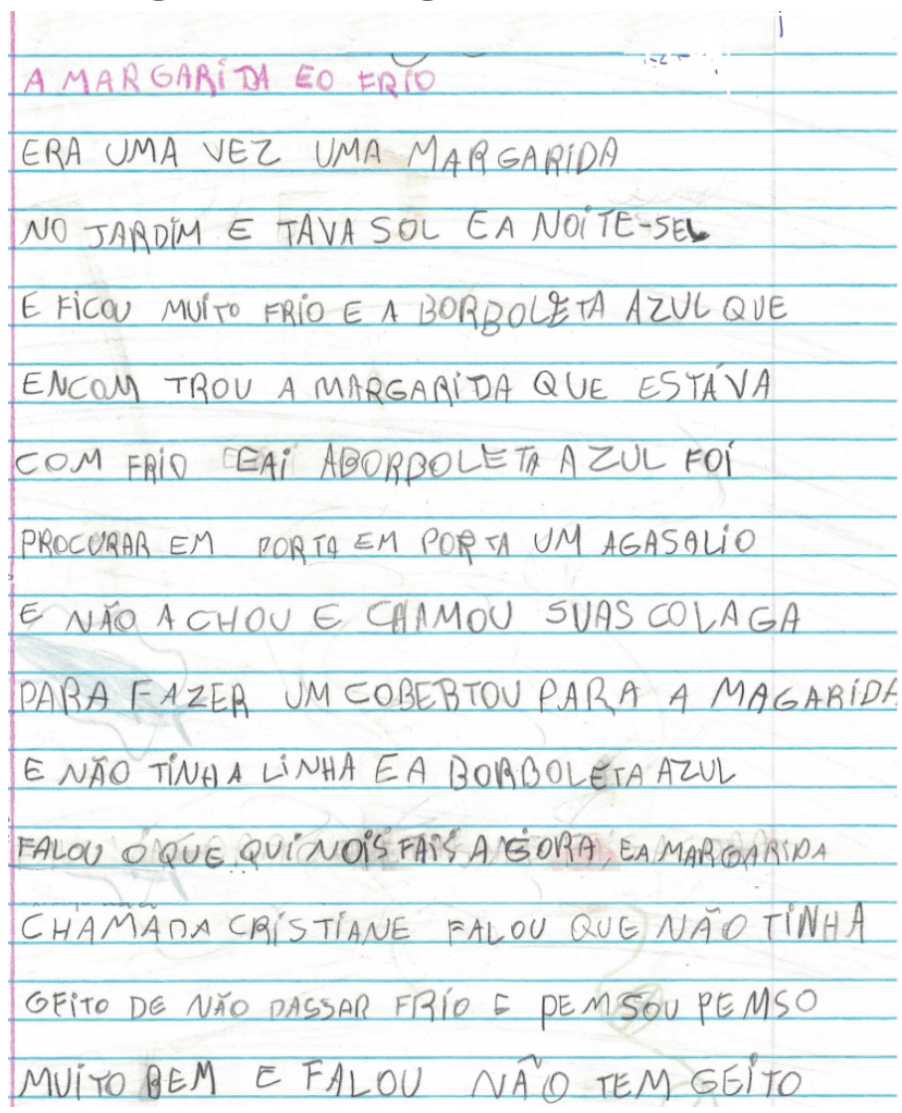

Fonte: Arquivo pessoal.

Data: 26 de julho de 2000.

Muitos aspectos do enunciado acima poderiam ser explorados a fim de refletir sobre o funcionamento das práticas e dos eventos de letramento, na perspectiva adotada aqui. Dados os limites impostos para um artigo, será destacado apenas um aspecto: a dife-

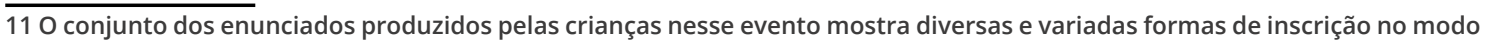
de enunciação escrito que não serão tematizados neste artigo, dados seus limites e seus propósitos. 
Práticas e eventos de letramento em pesquisas sobre escrita infantil Cristiane Carneiro Capristano

rença entre os momentos nos quais os fatos a serem narrados já tinham sido dados pelo destinatário imediato ${ }^{12} \mathrm{com}$ o qual a criança interagia (a professora e a história lida por ela) e os momentos em que os fatos a serem narrados precisavam ser constituídos pela criança, com base em suas próprias vivências simbólicas, já que não poderiam ser recuperados de um dizer imediato, preestabelecido. Esses dois momentos apontam para duas práticas de letramento convivendo no evento: de um lado, a prática de reescrever o dizer pré-estabelecido por um outro; por outro lado, o de escrever "livremente", de forma mais ou menos espontânea, momento no qual a decisão sobre quais ações narrar é, pelo menos aparentemente, da criança (cf. BRAGGIO, 1995, p. 133).

A fronteira entre os dois momentos do enunciado da criança, a meu ver, é sinalizada pela primeira vez na emergência de uma rasura, mostrada por um apagamento, feito na sexta linha, quando a criança registra $E A$ / (separado), depois apaga e, em cima do apagamento, insere $E A l$ (unido). Essa rasura indicia um movimento de retorno da criança sobre a sua escrita, uma parada (mostrada) sobre o movimento de escrever, um momento no qual sua enunciação "em vez de realizar-se, simplesmente [...], desdobra-se" (AUTHIER-REVUZ, 1998, p. 14). As rasuras na escrita infantil, como tenho defendido, são fatos de enunciação que constituem, no fio do dizer, "voltas reflexivas" (AUTHIER-REVUZ, 1998 e 2004), sinais da emergência do sujeito no intervalo aberto entre a instância enunciativa "que escreve" e a instância enunciativa "que vê"; instâncias distintas, portanto, não coincidentes (cf. LEMOS, 1999, 2002 e CAPRISTANO, 2013).

Rasuras não são, portanto, apenas vestígios de um texto não "passado a limpo", sobretudo quando se considera que podem existir lugares privilegiados para a sua emergência. A rasura em tela, por exemplo, ocorre justamente em um momento no qual se pode detectar uma mudança no enunciado da criança e, ao mes-

\footnotetext{
12 A produção de um enunciado sempre pressupõe um endereçamento (no sentido bakhtiniano). O endereçamento é um fenômeno complexo, já que se constitui pelo entrelaçamento de, pelo menos, três instâncias: destinatários imediatos, presumidos e o (s) sobredestinatário (s). Para uma discussão sobre o tema, conferir os diversos trabalhos do chamado Círculo de Bakhtin, em especial, Bakthin (2003).
} 
Práticas e eventos de letramento em pesquisas sobre escrita infantil Cristiane Carneiro Capristano

mo tempo, a interseção de duas práticas de letramento distintas, mobilizadas no evento de letramento aqui descrito.

A convivência entre essas duas práticas tem vários efeitos para o enunciado da criança, inclusive do ponto de vista de sua aproximação ou de seu distanciamento com relação às convenções ortográficas. Para ficar em apenas um exemplo, veja-se os dois primeiros registros do sintagma a borboleta azul (Linha 4 e 6). Quando o sintagma é diretamente recuperado do dizer cujo responsável é o destinatário imediato com o qual a criança interage (Linha 4), seu registro foi feito de forma convencional, respeitando a distribuição gráfica esperada pelas convenções ortográficas. Em contrapartida, quando a criança passa a registrar o modo como imagina que a Borboleta Azul teria ajudado a Margarida, o sintagma foi registrado, em parte, em dissonância com o esperado pelas convenções ortográficas, uma vez que a criança hipossegmenta o sintagma, registrando "aborboleta azul" (Linha 6).

A oscilação no registro de "a borboleta azul" não poderia ser compreendida de forma satisfatória como simples obra do acaso. Ela é fruto da convivência entre práticas letradas social e historicamente constituídas, ou seja, resulta da intersecção de regras relativamente anônimas e sempre fundamentalmente históricas, responsáveis, nas diferentes temporalidades instauradas nos eventos de letramento, por delimitar aquilo que pode e deve ser dito/escrito/lido/visto.

\section{Considerações Finais}

Neste artigo, o propósito foi refletir sobre quais outros sentidos poderiam ganhar os conceitos de prática e de evento de letramento, bem como a relação entre eles, quando vistos de uma perspectiva enunciativo-discursiva de linguagem (e, por conseguinte, de escrita). Essa reflexão foi feita em duas direções: primeiro, articulando as noções de práticas e de eventos de letramento, como entendidas em Street (2012 e 2014), com as noções de me- 
mória e de acontecimento, como propostas por Pêcheux (2010) e apropriadas por Corrêa (2007a, 2007b e 2013); depois, à luz dessa articulação, examinando enunciados escritos infantis resultantes de dois eventos de letramento escolares.

Em linhas bastante gerais, uma prática de letramento foi interpretada como aquilo (regras, lugares, posições, certos arranjos de tempo/espaço) que é possível de se tornar presente, por um efeito de memória (onde estão conjugados lembranças e esquecimentos sócio-historicamente constituídos), num evento de letramento. $O$ evento de letramento, por sua vez, foi compreendido como um acontecimento, um nó em uma rede (FOUCAULT, 2004, p. 26), o ponto de encontro entre uma novidade e uma memória (cf. CORRÊA, 2013, p. 335) e, portanto, como um momento de atualização contraditória (já que efeito de lembranças e de esquecimentos), de práticas sócio-históricas vivenciadas simbolicamente pelos sujeitos em diferentes tempos e espaços (TFOUNI, 2010).

Quando se trata de investigar a escrita infantil, pode-se dizer que essa compreensão dos eventos e das práticas de letramento permite ver os enunciados infantis como registros pontuais, singulares e, portanto, históricos do estado do processo discursivo em que a própria criança, enquanto escrevente, se situa (cf. CORRÊA, 2007a, p. 272). Permite, adicionalmente, reconhecer os enunciados infantis como registros complexos das experiências simbólicas vividas pelos sujeitos em diferentes tempos/espaços (sejam experiências satisfatórias ou não) e, nessa direção, olhar para os enunciados apreciando não só aquilo que neles se repete (regras, lugares, posições, certos arranjos de tempo/espaço), mas, também, pontos de ruptura, momentos em que o enunciado não se mostra tal e qual se esperaria nos eventos e nas práticas de letramento nos quais emerge. $\mathrm{Na}$ análise dos enunciados infantis - um deles apresentado primeiro em Braggio (1995) -, pôde-se, justamente, não só vislumbrar a emergência de modelos/padrões, mas recuperar pontos de ruptura (mostrados, às vezes, como pontos de interseção) que, nos eventos de letramento, indiciam o funcionamento complexo, dinâmico e heterogêneo das práticas de letramento. 


\section{Referências Bibliográficas}

AUTHIER-REVUZ, J. Palavras incertas: as não coincidências do dizer. São Paulo: Editora UNICAMP, 1998.

AUTHIER-REVUZ, J. Entre a transparência e a opacidade: um estudo enunciativo do sentido. Porto Alegre: EDIPUCS, 2004.

BAKHTIN, M. Os gêneros do discurso. In:BAKHTIN, M. Estética da criação verbal. Trad. Paulo Bezerra. 4. ed. São Paulo: Martins Fontes, p. 261-306, 2003.

BRAGGIO, S. L. B. Leitura e alfabetização: da concepção mecanicista à sociopsicolinguística. Porto Alegre: Artes Médicas, 1992.

BRAGGIO, S. L. B. A importância da construção do sentido na aquisição da linguagem escrita. In: BRAGGIO, S. L. B. Contribuições da linguística para alfabetização (Org). Goiânia: Editora da UFG, 1995, p. 125-139. CAPRISTANO, C. C. Segmentação na escrita infantil. São Paulo: Martins Fontes, 2007a.

CAPRISTANO, C. C. Mudanças na trajetória da criança em direção à palavra escrita. 2007b. Tese (Doutorado em Linguística Aplicada) - Instituto de Estudos da Linguagem - Universidade Estadual de Campinas, Campinas, 2007b.

CAPRISTANO, C. C. Por uma concepção heterogênea da escrita que se produz e que se ensina na escola. Cadernos de Educação, Pelotas, v. 1, p. 171-193, 2010.

CAPRISTANO, C. C. Um entre outros: a emergência da rasura na aquisição da escrita. Linguagem em (Dis)curso (Online), v. 13, p. 667-694, 2013.

CAPRISTANO, C. C.; CHACON, L. Relações metafóricas e metonímicas: notas sobre a "aquisição" da noção de palavra. In: TFOUNI, L. V; MARTHA, D. J. B. (Org.). O (in)esperado de Jakobson. 1ed. Campinas: Mercado das Letras, 2014, v. Único, p. 197-218.

CAPRISTANO, C. C.; CHACON, L. Uma análise quantitativa de rasuras ligadas à segmentação em enunciados produzidos no Ensino Fundamental I. Revista Linguística, v. 11, p. 216-229, 2016. 
CORRÊA, M. L. G. O modo heterogêneo de constituição da escrita. São Paulo: Martins Fontes, 2004.

CORRÊA, M. L. G. Pressupostos teóricos para o ensino da escrita: entre a adequação e o acontecimento. Filologia e Linguística Portuguesa, v. 9, p. 201-211, 2007a.

CORRÊA, M. L. G. Heterogeneidade da escrita: a novidade da adequação e a experiência do acontecimento. Filologia e Linguística Portuguesa, v. 8, p. 269-286, 2007b.

CORRÊA, M. L. G. Bases teóricas para o ensino da escrita. Linguagem em (Dis)curso (Impresso), v. 13, p. 481-513, 2013.

FOUCAULT, M. A arqueologia do saber. Rio de Janeiro: Forense Universitária, 2004.

LEMOS, C. T. G. Em busca de uma alternativa à noção de desenvolvimento na interpretação do processo de aquisição de linguagem: Parte II. Relatório FAPESP, Campinas, 1999.

LEMOS, C. T. G. Das vicissitudes da fala da criança e de sua investigação. Cadernos de Estudos Linguísticos, Campinas, v. 42, p. 41-70, 2002.

MACHADO, T. H. S.; CAPRISTANO, C. C. Rasuras ligadas à segmentação de palavras na aquisição da escrita. Educação em Revista, v. 32, n. 1, p. 337-364, 2016.

MAGALHÃES, I. (Org). Discurso e práticas de letramento. São Paulo: Mercado de Letras, 2012. p. 69-92.

PÊCHEUX, M. O discurso: estrutura ou acontecimento. Campinas: Pontes, 2006.

PÊCHEUX, M. Papel da memória. In: ACHARD, P. et al. (Org.) Papel da memória. Tradução e introdução José Horta Nunes. Campinas: Pontes, 2010. p. 49-57.

STREET, B. Literacy events and literacy practices: theory and practice in the New Literacy Studies. In: MARTIN-JONES, M.; JONES, K. (Orgs) Multilingual literacies, Amsterdã/Filadélfia: Jonh Benjamins, 2000. P. 17-29. 
Práticas e eventos de letramento em pesquisas sobre escrita infantil Cristiane Carneiro Capristano

STREET, B. Eventos de letramento e práticas de letramento: teoria e prática nos novos estudos de letramento. In: MAGALHÃES, I. (Org) Discurso e práticas de letramento. São Paulo: Mercado de Letras, 2012. p. 69-92.

STREET, B. Letramentos sociais: abordagens críticas do letramento no desenvolvimento, na etnografia e na educação. São Paulo: Parábola Editorial, 2014.

TFOUNI, L. V. Letramento e Alfabetização. 9. ed. São Paulo: Cortez Editora, 2010.

TFOUNI, L. V.; MONTE-SERRAT, D. M; MARTHA, D. J. B. A abordagem histórica do letramento: ecos da memória na atualidade. Scripta, Minas Gerais, v. 17, 2014. , p. 23-48. 